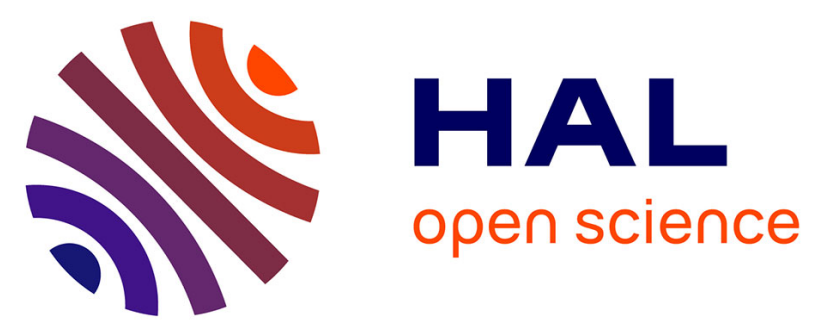

\title{
Geographically isolated but demographically connected: Immigration supports efficient conservation actions in the recovery of a range-margin population of the Bonelli's eagle in France
}

Nicolas Lieury, Aurélien Besnard, Cécile Ponchon, Alain Ravayrol, Alexandre

Millon

\section{To cite this version:}

Nicolas Lieury, Aurélien Besnard, Cécile Ponchon, Alain Ravayrol, Alexandre Millon. Geographically isolated but demographically connected: Immigration supports efficient conservation actions in the recovery of a range-margin population of the Bonelli's eagle in France. Biological Conservation, 2016, 195 (1), pp.272 - 278. 10.1016/j.biocon.2016.01.011 . hal-03559071

\section{HAL Id: hal-03559071 \\ https://hal-amu.archives-ouvertes.fr/hal-03559071}

Submitted on 5 Feb 2022

HAL is a multi-disciplinary open access archive for the deposit and dissemination of scientific research documents, whether they are published or not. The documents may come from teaching and research institutions in France or abroad, or from public or private research centers.
L'archive ouverte pluridisciplinaire HAL, est destinée au dépôt et à la diffusion de documents scientifiques de niveau recherche, publiés ou non, émanant des établissements d'enseignement et de recherche français ou étrangers, des laboratoires publics ou privés.

\section{(ㅇ)(1) $\$$}

Distributed under a Creative Commons Attribution - NonCommercial - NoDerivatives 44.0 


\title{
Geographically isolated but demographically connected: Immigration supports efficient conservation actions in the recovery of a range-margin population of the Bonelli's eagle in France
}

\author{
Nicolas Lieury ${ }^{\mathrm{a}, \mathrm{b}}$, Aurélien Besnard ${ }^{\mathrm{c}}$, Cécile Ponchon ${ }^{\mathrm{d}}$, Alain Ravayrol ${ }^{\mathrm{e}}$, Alexandre Millon ${ }^{\mathrm{a}, *}$

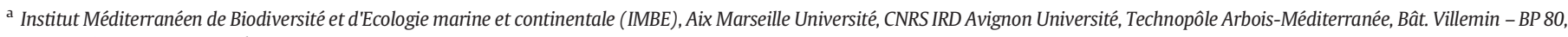 \\ F-13545 Aix-en-Provence Cedex 04, France \\ b Université de Lyon, F-69000, Lyon, Université Lyon 1, CNRS, UMR5558, Laboratoire de Biométrie et Biologie Evolutive, F-69622 Villeurbanne, France \\ c CEFE UMR 5175, CNRS - Université de Montpellier - Université Paul-Valéry Montpellier - EPHE, laboratoire Biogéographie et écologie des vertébrés, 1919 route de Mende, \\ F-34293 Montpellier cedex 5, France \\ d Conservatoire d'espaces naturels Provence-Alpes-Côtes-d Azur, Maison de la Crau, 2 Place Léon Michaud, F-13310 Saint-Martin de Crau, France \\ e La Salsepareille, 7 rue Lieutenant Fernand Pio, F-34800 Clermont-l'Hérault, France
}

\section{A R T I C L E I N F O}

\section{Article history:}

Received 2 October 2015

Received in revised form 13 January 2016

Accepted 18 January 2016

Available online $\mathrm{xxxx}$

\section{Keywords:}

Aquila fasciata

Immigration

Evidence-based Conservation

Integrated Population Model

Demography

\begin{abstract}
A B S T R A C T
Evidence is accumulating on the crucial role of spatial demographic processes, particularly immigration, in driving the viability of wild animal populations. However, the contribution of immigration is rarely accounted for when performing population viability analysis and evaluating the efficiency of conservation actions, which can lead to spurious inferences. Here we analysed a 24-year monitoring scheme conducted on the French population of Bonelli's eagle, a population considered as vulnerable and targeted by two recent conservation plans. This population is located at the northern range-margin of the species' range and has suffered a long-standing decline before recovering recently thanks to efficient conservation actions (mainly retrofitting of power lines). We combined all available demographic information sources into an Integrated Population Model (IPM) for quantifying the relative contribution of immigration and local demography to the overall population dynamics. Population projections derived from local demography strikingly differed from the observed population trajectory. Throughout the study period, a sustained immigration rate $(0.108 \pm 0.03$ immigrant females per occupied territory each year) first prevented the population to go extinct and then supported the recovery. The number of immigrants was about 1.0-1.5 times higher than the number of local recruits and we found only a weak evidence for a reduction in this ratio as survival rates increased. The fact that local conservation actions drove the recovery in mitigating anthropogenic perturbations revealed that range-margin populations should not be systematically considered as sink populations. Instead, demographic surveys should be promoted to assess the relative contribution of immigration and local demography alongside species' range (from centre to periphery) so as to improve our understanding of spatial demographic processes and ensure conservation actions are implemented at an appropriate spatial scale.
\end{abstract}

\section{Introduction}

The evaluation of species conservation plans often relies on the analysis of demographic surveys owing to identify the relative contribution of fecundity- and survival-related traits in the response of the population to conservation actions and/or environmental variations (Frederiksen et al., 2014). Demographic exchanges with surrounding populations are rarely investigated due to field constraints (but see Kendall et al., 2006) and managed populations are therefore often assumed to be closed for evaluating conservation actions. When modelling population dynamics through the estimation of survival,

\footnotetext{
* Corresponding author.

E-mail address: alexandre.millon@imbe.fr (A. Millon).
}

recruitment and reproduction, individuals leaving the study area (emigration) are ignored as they do not contribute to the growth of the population. In contrast, individuals born outside the study area -therefore typically unmarked- and entering the study area (immigration) are more problematic, as they can significantly contribute to population growth. Indeed, empirical evidence is accumulating on the influence of immigration on population dynamics (Abadi et al., 2010; Schaub et al., 2010, 2012, 2013; Brown and Collopy, 2012; Altwegg et al., 2014).

Integrating immigration in the evaluation of local conservation seems particularly relevant for the case of geographically-isolated populations situated at the margin of a species range, to evaluate whether a rescue effect is taking place. The ecological niche concept suggests that range-margin populations should dynamically behave like sink populations sustained by immigrants from source populations located in the 
core area (Guo et al., 2005; Lawton, 1993; Pulliam, 1988). This consideration typically questions the relevance of their conservation, since its long-term efficiency depends on the persistence of the immigration supply. Furthermore, local conservation actions may attract animals into sink habitats, thus potentially acting as ecological traps (Battin, 2004; Gilroy and Sutherland, 2007). Therefore, there is a pressing need for evaluation procedures accounting for immigration in the observed changes in population dynamics (Altwegg et al., 2014; Demerdzhiev et al., 2014; Schaub et al., 2010; Tauler et al., 2015). Recent developments in the modelling of population dynamics and the use of Integrated Population Models (IPM) in particular appears as particularly promising in this context. This approach consists in integrating all available information sources on demography (typically capture-recapture data, fecundity data and a population count) into a single modelling framework, and allows, among other things, to inference on demographic processes that are not directly measured, such as immigration (Besbeas et al., 2002; Schaub and Abadi, 2011).

Source-sink dynamics are expected to be common in fragmented populations of large territorial birds. This appears to be the case in particular for the Bonelli's eagle (Aquila fasciata) in western Europe, with the sub-populations in the south of the Iberian Peninsula thought to act as sources sustaining all surrounding populations (up to France), which would otherwise decline (Hernández-Matías et al., 2013; Fig. 1). Reduction in numbers and range of this relatively large-bodied raptor over Europe has been putatively linked to human-induced mortality of adults (mainly electrocution but also illegal killing by shooting and poisoning; Chevallier et al., 2015) and to the decline of main prey species (rabbits, partridges; Real and Mañosa, 1997). With the aim of halting the long-standing decline of the species at the northern margin of its range, two specific action plans have been launched in France since 1984. These plans specifically included a close monitoring of the population (from 1990 onwards) and the retrofitting of high-risk power lines (mainly low-voltage network, from 1998 onwards) within eagles' territories and other key areas hosting non-territorial birds (Burger et al., 2013). Chevallier et al. (2015) recently demonstrated a strong improvement of survival rates and a halt of the decline following the conservation actions. However, the discrepancy between population projections from locally-estimated demographic parameters and the observed trend in the number of pairs suggested that immigration was going on.

Our objective here was therefore to quantify the relative contribution of the recruitment of birds born locally on one hand and immigrants on the other hand, to the observed recovery of the French population of Bonelli's eagle. To implement such a demographic approach, we combined multiple sources of data (Capture-MarkResighting data, a fecundity survey, the recovery of dead individuals, and a count of the number of occupied territories) into a unique modelling framework (Integrated Population Model; Abadi et al., 2010; Szostek et al., 2014). The specific objectives of this study were to 1) estimate the mean annual number of immigrants recruiting into the French population so as to evaluate the level of demographic support received from the surrounding populations, 2) decipher the relative contribution of local recruits and immigrants to the overall population dynamics and 3 ) investigate the temporal variation in immigration rate, by taking advantage of the quasi-experimental setting offered by the recovery of the population following a severe decline. Regarding this last point, we predicted that the recovery of the population might have reduced immigration rate as a consequence of increased availability in locally-born individuals following the reduction in mortality by electrocution (Schaub et al., 2013). Alternatively, immigration rate may have changed irrespectively of local population dynamics but potentially in line with other source populations (Szostek et al., 2014). Disentangling between these two hypotheses have implications for conservation planning: the first one would emphasize the potential of local conservation actions to promote a self-supported population by eliminating anthropogenic threats that immigration contribute to buffer; whereas the second one would suggest that the persistence of this range-margin population is at least partially a by-product of source populations on which conservation efforts should be prioritized.

\section{Methods}

\subsection{The Bonelli's eagle in southern France}

The Bonelli's eagle is a medium-sized, long-lived raptor characterized by a relatively late onset of reproduction (4 years old in average;

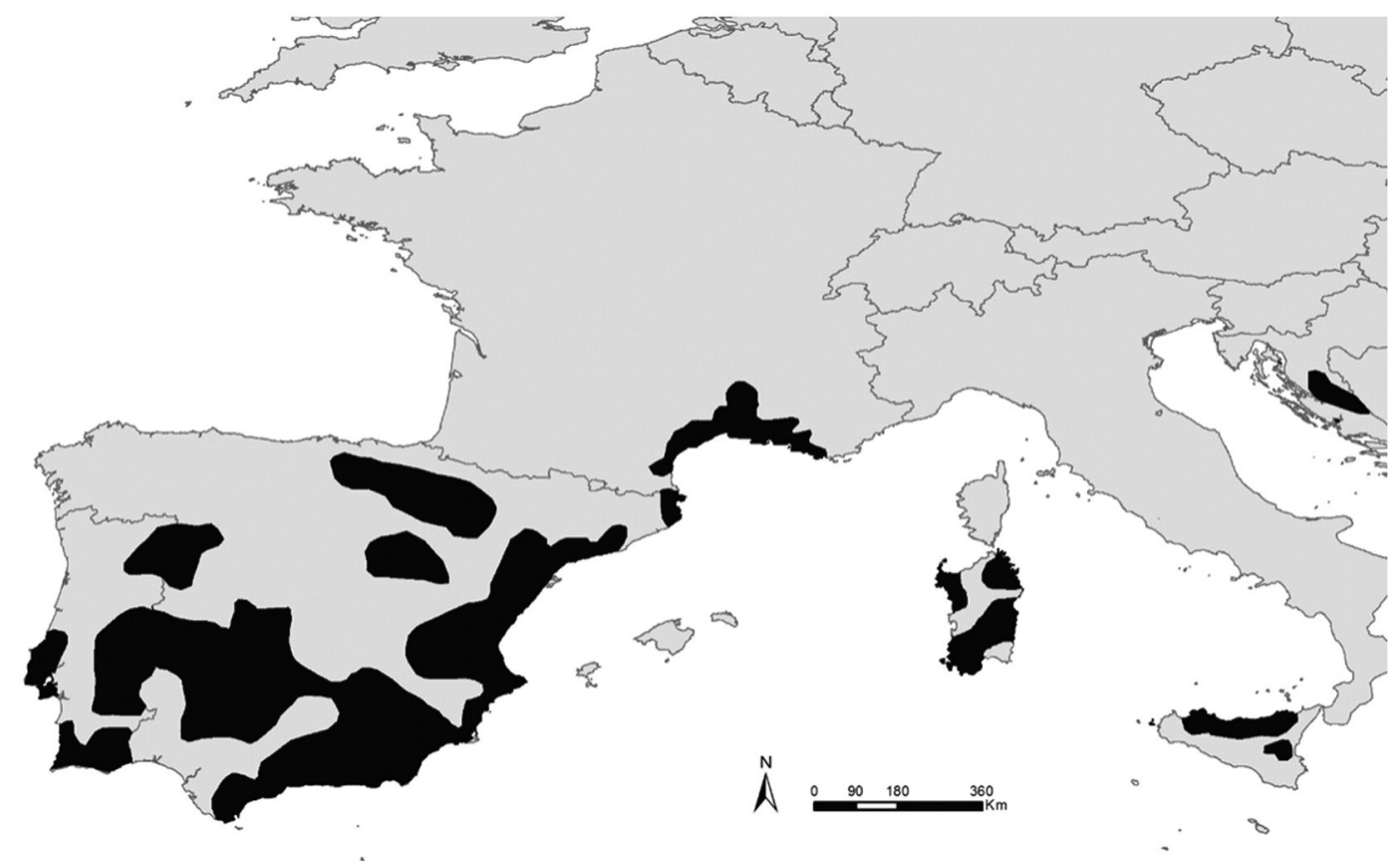

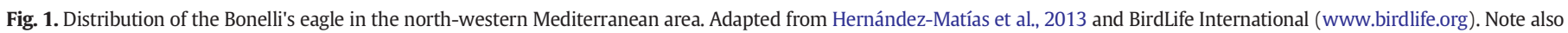
that a reintroduction programme is currently taking place on the Balearic Islands and that the Sardinian population is probably down to less than five pairs. 
Hernández-Matías et al., 2010), although some individuals attempt to breed when yearling. Both survival and fecundity rates are known to increase with the age of individuals and their experience in reproduction (Hernandez-Matias et al., 2011). This species is currently of least conservation concern, though declining, at the world level (IUCN, 2015). The population from western Europe is considered as near-threatened (BirdLife International, 2015).

The French population of Bonelli's eagle suffered from a strong decline of the number of territorial pairs from an estimated 80 pairs in the 1960's to less than 25 pairs by the end of the 1990's, concomitantly to a contraction of the breeding range (Burger et al., 2013). This population is restricted to the French Mediterranean area occupying open habitats such as scrubland and limestone hills with cliffs for nesting. It now appears geographically isolated from the nearest ensemble of breeding areas in Spanish Catalonia by the Pyrenees (54-130 km between closest pairs and core areas respectively; Fig. 1).

\subsection{Population monitoring}

We took advantage of a systematic monitoring scheme, involving ringing and a survey of reproduction, starting in 1990. Each spring, all known territorial pairs were closely monitored, and historicallyoccupied sites (including some abandoned before 1990) were checked for possible re-colonization (Burger et al., 2013). We defined this count of territorial pairs as population size. Repeated visits at occupied sites from mating to fledging periods were made to record the number of fledgling produced per pair (from 0 to 2), hereafter referred as fecundity. Capture-Resighting data were collected from 1990 to 2013. During this period, 524 out of 540 chicks (97\%) born in the population have been ringed at the nest before fledging with a conventional metal ring and a Darvic plastic ring with a short alphanumeric code that can be read using a telescope at a distance up to $200 \mathrm{~m}$ (Chevallier et al., 2015). Resighting data (212 events from 80 different individuals) consisted in resightings across the study area which was intensively monitored by different organizations, mostly in occupied territories but also within key areas used in winter or by non-breeding birds (e.g. Camargue, plain of la Crau). A total of 56 marked birds were recovered dead within the study area and then used to improve survival estimation (Burnham, 1993). As a consequence of Darvic ring loss, an intensive survey was implemented so as to read metal rings, and a majority of individuals having lost their Darvic ring were actually identified (Chevallier et al., 2015). However, and so as to remove any potential bias in the survival estimation, ring loss has been included as a state process in the capture-recapture model (see below).

\subsection{Demographic modelling and Integrated Populations Model}

Our main objective was to disentangle the relative contribution of local demography and immigration to the population dynamics of the Bonelli's eagle in France. By local demography, we meant the demographic processes occurring within the local population, apparent survival and fecundity leading to the recruitment of locally-born individuals, whereby a growth rate of the population can be derived which informs about the trajectory of the population in the absence of immigration. The IPM was composed of a Multi-State CaptureRecapture model (MSCR) estimating variation in local survival, a Poisson model estimating variation in fecundity. Those estimates were implemented into a Matrix Population model (MPM) for projecting population size over time. We used a demographic approach to investigate the influence of conservation plans on local survival (using MSCR) and its consequence on the population dynamics (using MPM), before estimating the immigration rate and its variations. We chose to build a single IPM structure parameterized taking advantage to the available scientific evidence (Hilborn and Mangel, 1997), previously collected on the Bonelli's eagle demography (Chevallier et al., 2015; Hernandez-Matias et al., 2011; Hernández-Matías et al., 2010).
The analysis of the joint capture-resighting-recovery (CR) data only estimated local survival (i.e. the combination of true survival and permanent emigration). Local survival rates were estimated using a multi-state approach combining data from resighting of live individuals and recoveries of dead birds (Burnham, 1993; Lebreton et al., 2009). Such models also enable to model simultaneously the probabilities of survival, recruitment and ring loss (Tavecchia et al., 2012). The multistate approach consists in decomposing CR histories in a succession of states and their associated observations. In our case, eagles in a given year could have been in one of these seven states: fledgling, floater with or without Darvic ring, territorial with or without Darvic ring, recently dead ( $<1$ year) or long dead ( $>1$ year). The latter defines an unobservable and absorbing state (i.e. individuals cannot move once in this state), in which individuals move into, the year following the recovery of their corpse (Lebreton et al., 1999; Schaub and Pradel, 2004). Each year, individuals can move from one state to another according to transition probabilities corresponding to survival, recruitment in a territory, and ring loss. These eagles could have been observed as fledgling, floater with or without Darvic ring, territorial with or without Darvic ring or recovered dead (see the state-transition and observation matrices in Supplementary material A). The parameterisation of such a model for the French population of Bonelli's eagle has been recently performed with a model selection approach using data collected between 1990 and 2009 (Chevallier et al., 2015). We used the same model structure, assuming this structure was not affected by additional data (dataset spanning up to 2013). More specifically, we parameterized survival probabilities according to the age of the birds (age 1,2-3,4+), with no difference between sexes (Hernandez-Matias et al., 2011). Resighting probabilities were age-dependent (age 1, 2,3+) and accounted for the loss of the Darvic ring (for birds aged $3+$, i.e. the vast majority of the observations; see Chevallier et al., 2015). The probability to be recruited at age $i$ varied according to the same age classes than resighting probabilities (Hernández-Matías et al., 2010). Chevallier et al. (2015) found that survival of all ages increased following the retrofitting of power lines. We therefore parameterised this effect by fitting a model with a distinct mean between periods (before/after the start of the retrofitting campaign, respectively 19901997 and 1998-2013), plus an annual random variation around them (Supplementary material B).

Goodness-of-fit tests (GOF) are not available for multi-state models including an absorbing state ('long-dead' individuals). As a surrogate, we performed Cormack-Jolly-Seber (CJS) GOF tests on resighted birds only using U-CARE 2.2.2 (Choquet et al., 2009). As lower survival of young individuals may generate spurious transience, we removed the first encounter in capture-recapture histories and accounted for agespecific survival in all models. The umbrella model adequately fitted the data (GOF tests: $\chi_{48}^{2}=26.1, P=0.99$ ).

Fecundity of Bonelli's eagles, expressed as the number of fledgling per territorial female, was modelled using a Poisson distribution of error including a random variation around the mean as well as the age and experience of the breeding females involved (four classes: inexperienced and experienced young females [ $<4$ year old], inexperienced and experienced old females [ $\geq 4$ years old]; Supplementary material C).

Finally, we built a matrix population model (post-breeding census) including six different stages (Supplementary material D; Caswell 2001). This MPM was female-based and assumed an even sex-ratio for the fledglings produced each year. We defined a compartment of floaters with four stages for age 1 to $4+$, and a compartment including territorial birds that differ in age and breeding experience: from age 1 to age $4+$ for birds breeding for the first time, and from age 2 to age $4+$ for experienced breeders. The transitions incorporated demographic stochasticity by sampling survival from a binomial distribution and fecundity from a Poisson distribution, for each individual. Environmental stochasticity was also modelled using annual random effect on fecundity and survival rates. The projection of the population size was then compared to the annual count of territorial pairs, with an observation 
error following a Gaussian distribution. The potential mismatch between predictions and observations was used in the integrated population model to estimate the number of immigrants recruited each year as territorials (Szostek et al., 2014). To limit the complexity of the model, we choose to constrain this estimation by modelling an average immigration rate with random annual variation. This immigration rate was defined as the number of female immigrants newly territorial in year $t+1$ per number of territorial females in year $t$ (Abadi et al., 2010). Finally, we tested for a linear relationship between immigration rate and the annual number of new local recruits.

We used a Bayesian framework to analyse the IPM, combining the joint likelihood with prior probability distributions to obtain posterior distributions of the target parameters (Kéry and Schaub, 2012). Because all previous parameter estimations in the literature were extracted from the same data set, we could not use them as informative priors in our model. Therefore, we checked the sensitivity of each parameter only by changing uninformative priors. The priors for effect size of the different covariates (power lines retrofitting on survival and temporal trends of immigration) were centred on 0 . These effects were considered significant when the $95 \%$ of their posterior distribution did not overlap zero (Grosbois et al., 2008). We applied the Markov Chain Monte Carlo (MCMC) method to simulate observations from the posterior distributions in WinBUGS (Lunn et al., 2000) which was run from $\mathrm{R}$ (package R2WinBUGS; Sturtz et al., 2005). We specified a burn-in of 40000 and simulated 90000 samples that were thinned by a factor 10 and ran 2 chains with different starting values. Inference was therefore obtained by 10,000 samples from posterior distributions. Convergence of the Markov chains was satisfactory in each case $(R<1.05)$. The complete BUGS code is given in Supplementary material E.

\section{Results}

The French population of Bonelli's eagles went down to 22 pairs in 2002, the lowest point of a long-standing decline. Following the retrofitting of power lines, the populations recovered to reach 30 pairs in 2013 (31 in 2011). This recovery was achieved through the reoccupancy of historically-occupied sites (including some abandoned before 1990). Only two 'truly new' sites have been colonized but immediately detected via the monitoring of other cliff-nesting raptors. Modelled population growth rates based on period-specific demographic rates showed a shift from a strongly declining to an almost stable local demography ( $\lambda_{\text {mod.1990-1997 }}=0.888$ with $95 \% \mathrm{CI}$ : [0.8710.898 ] vs. $\lambda_{\text {mod.1998-2013 }}=0.989$ [0.976-0.991]; Fig. 2). Concurrently, local survival rates increased after the beginning of conservation plans in 1998 (Supplementary material B). These survival estimates accounted for age-specific resighting probabilities (respectively 0.11 , 0.22 and 0.63 for age 1 , age 2 and age $3+$ birds) and for ring loss (down to 0.38 for age $3+$ birds having lost their Darvic ring). When this observed increase in survival rates (across all ages) was combined to other demographic rates estimated during the first period (19901997), the modelled population growth rate increased from 0.879 to 0.980 . This result indicates that improved local survival rates as a consequence of conservation actions was the main driver behind the shift in population dynamics.

Nevertheless, the projection of the local population dynamics did not match with the observed recovery of the population $\left(\lambda_{\text {mod.1990-2013 }}=0.948\right.$ [0.932-0.963] vs. $\lambda_{\text {obs.1990-2013 }}=1.022$; Fig. 2). The IPM, explicitly including immigration as a demographic process, estimated that between 2 and 4 immigrant females were recruited annually (mean $=2.85 \pm 0.45$ ), corresponding to an average immigration rate of $0.108 \pm 0.03$ (number of immigrant females per occupied territory and per year; Fig. 3). Before conservation actions took place, the estimated number of immigrants exceeded by around 1.5 times the number of local recruits. Since 1998, the proportion of recruited immigrants remained roughly constant while the recruitment of local birds slightly increased, until both sources of recruitment became

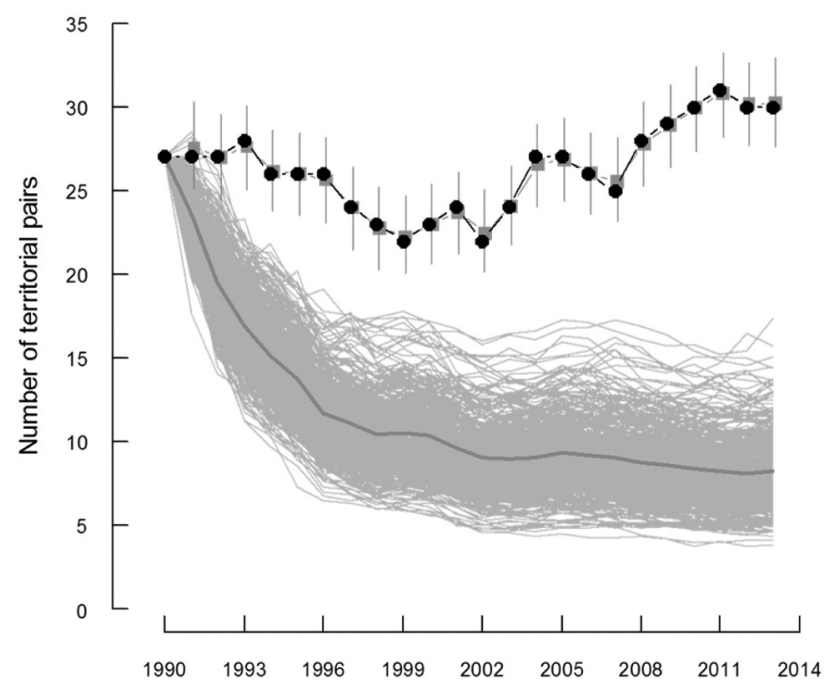

Fig. 2. Projections of the Bonelli's eagle population local dynamics compared to the count of territorial pairs monitored between 1990 and 2013. Predictions from the Integrated Population Model (IPM in grey squares, accounting for immigration) and its $95 \%$ confidence interval closely match the observed population trend (black dots). To compare with a model that does not account for immigration, we drew 500 projections from the stochastic matrix model (light grey lines) using local demographic rates (apparent survival and fecundity). The thick dark grey line corresponds to the prediction from a deterministic model using mean parameter estimates.

equal (Fig. 3). This negative relationship between immigration and local recruitment rates was however not statistically significant $(\beta=-0.06[-0.29 ; 0.09])$. Consequently, it can be said that the positive shift in the eagle population dynamics was not due to an increase of the immigration rate.

\section{Discussion}

By combining all available information sources into an Integrated Population Model (IPM), we were able to decipher the demographic processes underpinning the recent recovery observed in the French population of Bonelli's eagle. In particular, this integrated framework allowed us to estimate the importance of immigration in eagle's

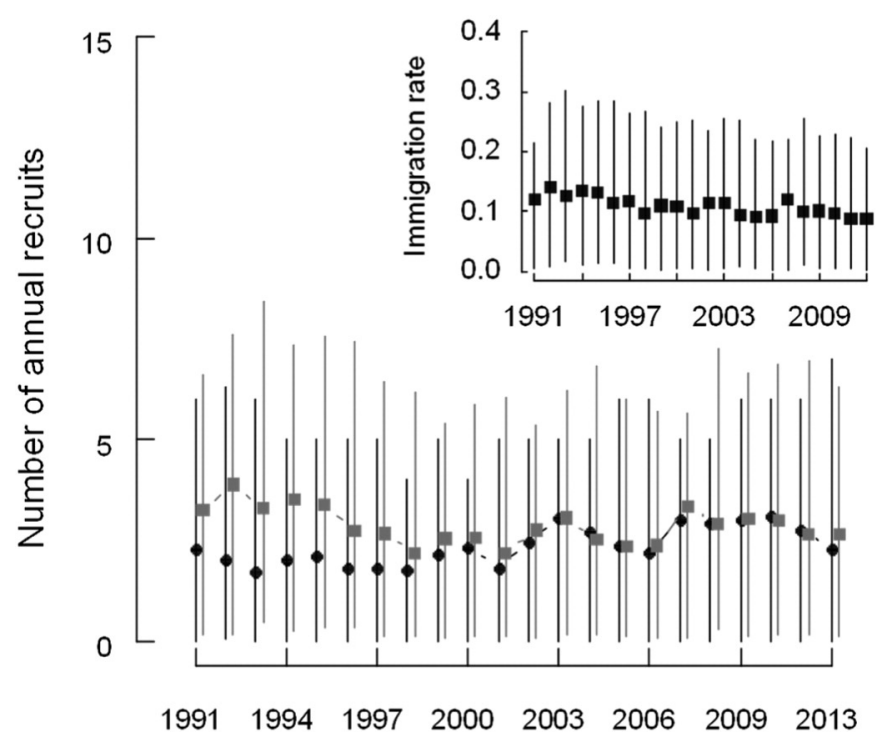

Fig. 3. Estimations of the annual number of recruited immigrants in the Bonelli's eagle population compared to the number of local recruits as estimated by the IPM. Segments represents $95 \%$ of the posterior distribution around the mean number of immigrants (grey squares) and local recruits (filled circles). Inserted panel: annual variation in immigration rate from which are derived the estimates for the number of immigrants. 
population dynamics. Despite being relatively geographically-isolated at the northern margin of the species distribution (Fig. 1), this population benefited from a sustained and apparently constant immigration rate of about $11 \%$, i.e. roughly two immigrant birds being recruited annually per 10 territorial pairs. More immigrants recruited into the French population that birds born locally during the decline phase, but the immigrant:local recruits ratio tended to diminish progressively to equal almost exactly one, during the recovery phase following the retrofitting of power lines.

\subsection{Evaluating the efficiency of conservation actions through an integrated demographic approach}

The conservation plan implemented by the end of the 1990's was successful in halting the long-standing decline and even allowed the population of Bonelli's eagle in France to slightly recover over the last 15 years. In particular, the retrofitting of the most dangerous power lines (mainly low-voltage networks) increased survival for all age classes (this study, Chevallier et al., 2015). Based on locally-estimated demographic parameters, the population model projected that the population shifted from a strongly declining trend to a stable situation (from 27 territorial pairs in 1990 to around 7-10 from 1999 onwards). However, this projection strikingly differed from the observed number of territorial pairs, which progressively increased from 22 in 2002 to 30 pairs in 2013, following an initial decline phase ( 27 pairs in 1990 down to 22 pairs in 1999; Fig. 2). The combination of different sources of demographic data into a unique IPM allowed us to explain the divergence between projections and observations by the occurrence of immigration at a rate of about $11 \%$. Thus, a sustained immigration rescued the population by slowing down the decline before the main campaign of power lines' retrofitting took place from 1998. Thereafter, immigrant recruits reinforced a roughly stable local demography and allowed the population to actually increase.

Our results indicated that about three immigrant females (most likely from Spain) were recruited each year in the French population. Note that this result entails an equal number of immigrant males to be recruited as we assumed similar demographic rates for either sex. This level of demographic connection between Spanish and French populations of Bonelli's eagle is actually in line with field data. Indeed, as almost all chicks have been ringed in the closely monitored French population since 1990 (97\%; see Methods), observed unmarked birds recruiting into the population can almost certainly be assigned as immigrants. On average, 2.7 unmarked females and 3.7 unmarked males recruited annually in the population between 1997 and 2010, hence closely matching model predictions (Burger et al., 2013). As a second piece of evidence, six eagles ringed as chicks in Spain (from a coloured-ringing scheme launched in Catalonia in 2008; Real et al., 2015) were recruited in France out of the documented 36 recruitments over the last four breeding seasons (17\%; authors' unpublished data). Note that there was an even number of males and females in these Spanish birds recruited in France, therefore indicating that the slight tendency of males to disperse shorter distances compared to females (Real and Manosa, 2001) did not preclude immigration of either sex to occur between Spain and France. Altogether, this provides strong empirical support to the conclusion of a multi-site population viability analysis conducted on the species, underlining the importance of relatively large-scale dispersal in the dynamics of west-European populations (Hernández-Matías et al., 2013).

The annual variation in the number of recruits showed a slight increase over time in the number of locally-born individuals, while the number of immigrants remained fairly stable. Interestingly, the immigrant:local recruits ratio decreased over the study period to reach an almost equal number of these two categories from 2000 onwards. This result is to some extent in line with our predictions that increased survival following power lines' retrofitting would benefit local recruitment to the detriment of the recruitment of immigrants.
This suggests that immigration may have compensated for the anthropogenic mortality before the main conservation action took place and then may have been regulated as the population increased. The level of uncertainty around the estimates however precludes any firm conclusion about these temporal trends (Fig. 3). Nevertheless, increased survival across all ages entailed fewer turnovers in occupied territories and higher availability of floaters, thus higher competition for territory access. It has been suggested that locally-born individuals have priority access to vacant territories over immigrant birds, as they typically benefit from longer on-site experience. It remain unclear however whether delayed recruitment of immigrants is due to lower experience or lower quality of individuals immigrating (Doligez and Pärt, 2008; Julliard et al., 1996; Millon et al., 2010). For species, such as the Bonelli's eagle, in which the floating stage may last several years, this question remains open as immigrant birds may reach the new population as juvenile and therefore gain similar experience. Indeed, given the paucity of information on non-breeding birds, we structured the IPM so as to estimate recruitment of immigrants in a territory but not as non-breeders. We have very little idea yet on the timing of dispersal but future studies involving the equipment of juvenile eagles with tracking device may help to clarify this point.

\subsection{Considering spatial demographic processes for conservation planning}

Despite the improvement in survival following conservation actions, the French population of Bonelli's eagle could still be categorized as a sink population as its local demography remains slightly negative (current predicted $\lambda$ from local demographic parameters: 0.989 ). A naïve cost-benefit approach could thus argue that investing financial and human resources in its conservation would be inefficient in a long run and should be reallocated on Spanish source populations, that are also affected by anthropogenic perturbations (Real and Mañosa, 1997). Several elements suggest we should not follow this over-simplistic view.

First, we showed that if immigration initially buffered the loss due to electrocution and sustained the population of Bonelli's eagle in France, immigration alone was not responsible for the observed shift from a negative to a positive population trend. Given that residual humaninduced mortality sources have been identified (electrocution, illegal killing; Burger et al., 2013), the studied population has the potential to become a source provided that appropriate conservation actions will be undertaken. Specifically, an absolute increase of 3\% in adult survival (or of $14 \%$ in immature survival) would make the population selfsustainable (Chevallier et al., 2015).

Second, emigration have also been documented with recruitments of birds born in France recorded in Catalonia (authors' unpublished data). Yet, data on emigration were too scarce for testing the occurrence of a relationship between immigration and emigration processes, potentially compensating each other (Doncaster et al., 1997; Runge et al., 2006). Interestingly, the Catalan population actually underwent a trajectory similar to the French population, with a strong decline until 2000 followed by a recovery (Real et al., 2015). The intensive monitoring now in place in the closest Spanish population of Bonelli's eagle (Catalonia) should soon offer a unique opportunity to gather information on spatial demographic processes, immigration and also emigration, in long-lived territorial birds (Hernández-Matías et al., 2013; Oro, 2003). Furthermore, it would be interesting to apply IPM for estimating the extent of variation in immigration rate among several populations from the centre to the edge of the species distribution range. The classical source-sink model would predict that immigration rate would reduce from the edge to reach a value close to zero at the centre. Alternatively, immigration may be a demographic process occurring at a minimum level across all populations (Doncaster et al., 1997). This knowledge on spatial demographic processes might be particularly useful to inform large-scale efficient conservation actions of vulnerable species (Salafsky et al., 2002), such as many large raptors in Europe, and provide relevant evidence on which prioritization of conservation 
actions over a population network exhibiting source-sink dynamics could be based.

Lastly, we want to stress here the often overlooked role of rangemargin populations in the persistence of the whole network of fragmented populations. Indeed, Howe et al. (1991) demonstrated through simulations that range-margin sink populations (provided that they are not too numerous), may actually be beneficial to the ensemble by stopping immigrants, that otherwise would have been lost in unsuitable habitats. The Bonelli's eagle population in France, by its localisation at the northern edge of the European distribution of the species, may well play this role.

In conclusion, our work provided further evidence of the crucial role of immigration in shaping the dynamics of bird populations (Brown and Collopy, 2012; Lieury et al., 2015; Schaub et al., 2010, 2012, 2013; Tauler et al., 2015; Tempel et al., 2014). The fact that immigration depends on processes occurring outside managed areas challenges the idea that conservation could entirely determine local population dynamics (Tempel et al., 2014). This further points out that the spatial scale of management may not match the ecological spatial scale at which demographic processes take place and that cross-border conservation actions should be promoted (Oro, 2003).

\section{Acknowledgements}

We are grateful to the local network of volunteers and collaborators helping in monitoring the Bonelli's eagle population since 1990. The ringing programme is ethically approved by CRBPO. This study was funded by two species action plan between 1999 and 2009, and otherwise by DREAL-LR and DREAL-PACA. NL received a PhD grant from Ecole Normale Supérieure throught the ED Sciences de l'Environnement (Aix Marseille Université). Thank you to G. Astruc for her help with GIS.

\section{Supplementary data}

Supplementary data to this article can be found online at http://dx. doi.org/10.1016/j.biocon.2016.01.011.

\section{References}

Abadi, F., Gimenez, O., Ullrich, B., Arlettaz, R., Schaub, M., 2010. Estimation of immigration rate using integrated population models. J. Appl. Ecol. 47, 393-400. http://dx.doi.org/ 10.1111/j.1365-2664.2010.01789.x

Altwegg, R., Jenkins, A., Abadi, F., 2014. Nestboxes and immigration drive the growth of an urban Peregrine Falcon Falco peregrinus population. Ibis (Lond. 1859) 156, 107-115. http://dx.doi.org/10.1111/ibi.12125.

Battin, J., 2004. When good animals love bad habitats: ecological traps and the conservation of animal populations. Conserv. Biol. 18, 1482-1491. http://dx.doi.org/10.1111/j. 1523-1739.2004.00417x.

Besbeas, P., Freeman, S.N., Morgan, B.J.T., Catchpole, E.A., 2002. Integrating markrecapture-recovery and census data to estimate animal abundance and demographic parameters. Biometrics 58, 540-547. http://dx.doi.org/10.1111/j.0006-341X.2002 00540.x.

Brown, J.L., Collopy, M.W., 2012. Immigration stabilizes a population of threatened cavitynesting raptors despite possibility of nest box imprinting. J. Avian Biol. 43, 1-8. http:// dx.doi.org/10.1111/j.1600-048X.2012.05728.x.

Burger, J., Hiessler, N., Ponchon, C., Vincent-Martin, N., 2013. Plan national d'actions en faveur de l'aigle de Bonelli Aquila fasciata (2014-2023). Ministère de l'environnement et du développement durable et de l'énergie.

Burnham, K.P. 1993. A theory for combined analysis of ring recovery and recapture data. In: Lebreton, J.-D., North, P.M. (Eds.), Marked Individuals in the Study of Bird Population. Birkhauser Verlag, Basel, Switzerland, pp. 199-213.

Chevallier, C., Hernandez-Matias, A., Real, J., Vincent-Martin, N., Ravayrol, A., Besnard, A 2015. Retrofitting of Power Lines Effectively Reduces Mortality by Electrocution in Large Birds: An Example with the Endangered Bonelli's Eagle. J. Appl. Ecol.

Choquet, R., Lebreton, J.-D., Gimenez, O., Reboulet, A.M., Pradel, R., 2009. U-CARE: utilities for performing goodness of fit tests and manipulating CApture-REcapture data. Ecography (Cop.) 32, 1071-1074.

Demerdzhiev, D., Stoychev, S., Dobrev, D., Spasov, S., Oppel, S., 2014. Studying the demographic drivers of an increasing Imperial Eagle population to inform conservation management. Biodivers. Conserv. 24, 627-639. http://dx.doi.org/10.1007/s10531 014-0841-0.

Doligez, B., Pärt, T., 2008. Estimating fitness consequences of dispersal: a road to "knowwhere"? Non-random dispersal and the underestimation of dispersers' fitness. J. Anim. Ecol. 77, 1199-1211.
Doncaster, C.P., Clobert, J., Doligez, B., Gustafsson, L., Danchin, E., 1997. Balanced dispersal between spatially varying local populations: an alternative to the source-sink model. Am. Nat. 150, 425-445.

Frederiksen, M., Lebreton, J.-D., Pradel, R., Choquet, R., Gimenez, O., 2014. Identifying links between vital rates and environment: a toolbox for the applied ecologist. J. Appl. Ecol. 51, 71-81. http://dx.doi.org/10.1111/1365-2664.12172.

Gilroy, J.J., Sutherland, W.J., 2007. Beyond ecological traps: perceptual errors and undervalued resources. Trends Ecol. Evol. 22, 351-356. http://dx.doi.org/10.1016/j. tree.2007.03.014.

Grosbois, V., Gimenez, O., Gaillard, J.M., Pradel, R., Barbraud, C., Clobert, J., Moller, A.P., Weimerskirch, H., 2008. Assessing the impact of climate variation on survival in vertebrate populations. Biol. Rev. 83, 357-399.

Guo, Q., Taper, M., Schoenberger, M., Brandle, J., 2005. Spatial-temporal population dynamics across species range: from centre to margin. Oikos 108, 47-57.

Hernández-Matías, A., Real, J., Pradel, R., Ravayrol, A., Vincent-Martin, N., Bosca, F., Cheylan, G., 2010. Determinants of territorial recruitment in Bonelli's Eagle (Aquila fasciata) populations. Auk 127, 173-184. http://dx.doi.org/10.1525/auk.2009.09143.

Hernandez-Matias, A., Real, J., Pradel, R., 2011. Effects of age, territoriality and breeding on survival of Bonelli's Eagle Aquila fasciata. Ibis (Lond. 1859) 153, 846-857.

Hernández-Matías, A., Real, J., Moleaon, M., Palma, L., Sanchez-Zapata, J.A., Pradel, R., Carrete, M., Gil-Sánchez, J.M., Beja, P., Balbontin, J., Vincent-Martin, N., Ravayrol, A., Benitez, J.R., Arroyo, B., Fernandez, C., Ferreiro, E., Garcia, J., 2013. From local monitoring to a broad-scale viability assessment: a case study for the Bonelli's Eagle in western Europe. Ecol. Monogr. 83, 239-261.

Hilborn, R., Mangel, M., 1997. The Ecological Detective: Confronting Models with Data. Princeton University Press, New Jersey.

Howe, R.W., Davis, G.J., Mosca, V., 1991. The demographic significance of "sink" populations. Biol. Conserv. 57, 239-255. http://dx.doi.org/10.1016/0006-3207(91)90071-G.

BirdLife International, 2015. European Red List of Birds [WWW Document]. URL http:// www.birdlife.org/datazone/info/euroredlist.

IUCN, 2015. The IUCN red list of threatened species [WWW Document]. URL http://www. iucnredlist.org.

Julliard, R., Perret, P., Blondel, J., 1996. Reproductive strategies of philopatric and immigrant blue tits. Acta Oecol. 17, 487-501.

Kendall, W.L., Conn, P.B., Hines, J.E., 2006. Combining multistate capture-recapture data with tag recoveries to estimate demographic parameters. Ecology 87, 169-177.

Kéry, M., Schaub, M., 2012. Bayesian Population Analysis Using WinBUGS: A Hierarchical Perspective. Academic Press.

Lawton, J.H., 1993. Range, population abundance and conservation. Trends Ecol. Evol. 8, 409-413.

Lebreton, J.-D., Almeras, T., Pradel, R., 1999. Competing events, mixtures of information and multistrata recapture models. Bird Study 46, 39-46.

Lebreton, J.D., Nichols, J.D., Barker, R.J., Pradel, R., Spendelow, J.A., 2009. Modelling individual animal histories with multistate capture-recapture models. Adv. Ecol. Res. 41, 87-173.

Lieury, N., Gallardo, M., Ponchon, C., Besnard, A., Millon, A., 2015. Relative contribution of local demography and immigration in the recovery of a geographically-isolated population of the endangered Egyptian vulture. Biol. Conserv. 191, 349-356. http://dx. doi.org/10.1016/j.biocon.2015.07.008.

Lunn, D.J., Thomas, A., Best, N., Spiegelhalter, D., 2000. WinBUGS - a Bayesian modelling framework: concepts, structure and extensibility. Stat. Comput. 10, 325-337.

Millon, A., Petty, S.J., Lambin, X., 2010. Pulsed resources affect the timing of first breeding and lifetime reproductive success of tawny owls. J. Anim. Ecol. 79, 426-435.

Oro, D., 2003. Managing seabird metapopulations in the Mediterranean: constraints and challenges. Sci. Mar. 67, 13-22

Pulliam, R.H., 1988. Sources, sinks, and population regulation. Am. Nat. 132, 652-661.

Real, J., Mañosa, S., 1997. Demography and conservation of Western European Bonelli's Eagle Hieraaetus fasciatus populations. Biol. Conserv. 79, 59-66. http://dx.doi.org/10. 1016/S0006-3207(96)00100-0.

Real, J., Manosa, S., 2001. Dispersal of juvenile and immature Bonelli's Eagles in northeastern Spain. J. Raptor Res. 35, 9-14

Real, J., Hernandez-Matias, A., Rollan, A., Tinto, A., 2015. El Aguila perdicera en Cataluna: de la amenaza a la conservacion. Barcelona, Spain.

Runge, J.P., Runge, M.C., Nichols, J.D., 2006. The role of local populations within a landscape context: defining and classifying sources and sinks. Am. Nat. 167, 925-938. http://dx.doi.org/10.1086/503531.

Salafsky, N., Margoluis, R., Redford, K.H., Robinson, J.G., 2002. Improving the practice of conservation: a conceptual framework and research agenda for conservation science. Conserv. Biol. 16, 1469-1479. http://dx.doi.org/10.1046/j.1523-1739.2002.01232.x.

Schaub, M., Abadi, F., 2011. Integrated population models: a novel analysis framework for deeper insights into population dynamics. J. Ornithol. 152, 227-237. http://dx.doi. org/10.1007/s10336-010-0632-7.

Schaub, M., Pradel, R., 2004. Assessing the relative importance of different sources of mortality from recoveries of marked animals. Ecology 85, 930-938.

Schaub, M., Aebischer, A., Gimenez, O., Berger, S., Arlettaz, R., 2010. Massive immigration balances high anthropogenic mortality in a stable eagle owl population: lessons for conservation. Biol. Conserv. 143, 1911-1918. http://dx.doi.org/10.1016/j.biocon.2010.04.047.

Schaub, M., Reichlin, T., Abadi, F., Kéry, M., Jenni, L., Arlettaz, R., 2012. The demographic drivers of local population dynamics in two rare migratory birds. Oecologia 168 , 97-108. http://dx.doi.org/10.1007/s00442-011-2070-5.

Schaub, M., Jakober, H., Stauber, W., 2013. Strong contribution of immigration to local population regulation: evidence from a migratory passerine. Ecology 94 , 1828-1838. http://dx.doi.org/10.1890/12-1395.1.

Sturtz, S., Ligges, U., Gelman, A., 2005. R2WinBUGS: a package for running WinBUGS from R. J. Stat. Softw. 12, 1-16.

Szostek, K.L., Schaub, M., Becker, P.H., 2014. Immigrants are attracted by local prebreeders and recruits in a seabird colony. J. Anim. Ecol. 1-10. http://dx.doi.org/10. $1111 / 1365-2656.12206$. 
Tauler, H., Real, J., Hernández-Matías, A., Aymerich, P., Baucells, J., Martorell, C., Santandreu, J., 2015. Identifying key demographic parameters for the viability of a growing population of the endangered Egyptian Vulture Neophron percnopterus. Bird Conserv. Int. 1-14 http://dx.doi.org/10.1017/S0959270914000392.

Tavecchia, G., Adrover, J., Navarro, A.M., Pradel, R., 2012. Modelling mortality causes in longitudinal data in the presence of tag loss: application to raptor poisoning and electrocution. J. Appl. Ecol. 49, 297-305. http://dx.doi.org/10.1111/j.1365-2664. 2011.02074.x.

Tempel, D.J., Peery, M.Z., Gutiérrez, R.J., 2014. Using integrated population models to improve conservation monitoring: California spotted owls as a case study. Ecol. Model. 289, 86-95. http://dx.doi.org/10.1016/j.ecolmodel.2014.07.005. 